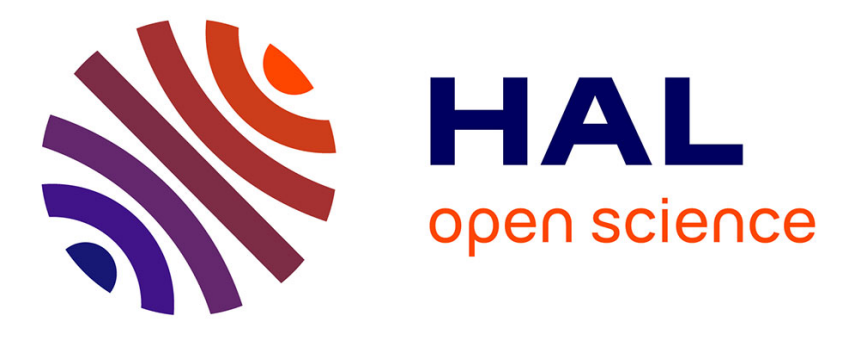

\title{
Applicability of Planning and Control in a Port Environment
}

Peter Bjerg Olesen, Cecilie Maria Damgaard, Hans-Henrik Hvolby, Iskra

Dukovska-Popovska

\section{- To cite this version:}

Peter Bjerg Olesen, Cecilie Maria Damgaard, Hans-Henrik Hvolby, Iskra Dukovska-Popovska. Applicability of Planning and Control in a Port Environment. IFIP International Conference on Advances in Production Management Systems (APMS), Sep 2014, Ajaccio, France. pp.555-562, 10.1007/9783-662-44739-0_68. hal-01388594

\section{HAL Id: hal-01388594 \\ https://hal.inria.fr/hal-01388594}

Submitted on 27 Oct 2016

HAL is a multi-disciplinary open access archive for the deposit and dissemination of scientific research documents, whether they are published or not. The documents may come from teaching and research institutions in France or abroad, or from public or private research centers.
L'archive ouverte pluridisciplinaire HAL, est destinée au dépôt et à la diffusion de documents scientifiques de niveau recherche, publiés ou non, émanant des établissements d'enseignement et de recherche français ou étrangers, des laboratoires publics ou privés.

\section{(c)(1)}

Distributed under a Creative Commons Attribution| 4.0 International License 


\title{
Applicability of planning and control in a port environment
}

\author{
Peter Bjerg Olesen*, Cecilie Maria Damgaard, Hans-Henrik Hvolby, Iskra Dukov- \\ ska-Popovska \\ Centre for Logistics, Department for mechanical and manufacturing engineering, Aalborg \\ University, Denmark \\ *pbo@celog.dk, cecilie@celog.dk, hhh@celog.dk, iskra@celog.dk
}

\begin{abstract}
There is a lot of focus on intermodal transportation, maritime efficiency and port governance in the literature, but there is little regarding how to plan and coordinate activities in ports, especially in the context of small and medium sized ports. This paper will approach the planning tasks in port by using knowledge from the well-investigated field of planning and control in manufacturing and make use of the structure of strategic, tactical and operational planning, but relating this to the non-hierarchical setup found in most smaller ports. The paper finds that the general planning functions found in manufacturing planning and control can be applicable if approached as a way to align capacity and demand, and not focusing on the methods in the planning functions.
\end{abstract}

Keywords: Port, planning, coordination, non-hierarchical, maritime

\section{Introduction}

Historically, ports in Denmark and Europe have been owned by the government and have primarily operated as landlord for other companies and as provider of dock and crane resources [1]. Because the port authorities have operated as landlords, they have had little focus on developing and streamlining the operations in the ports. Specifically there has been little focus on improving the competiveness of the logistic system, as they have not been taking part in this aspect, as stated by the port management of the case port. The lack of involvement in the logistic activities has meant there is no systematic coordination within the port system. In the manufacturing industry, planning and control $(\mathrm{P} \& \mathrm{C})$ have been used for many years to aide companies with aligning capacity and demand as well as coping with uncertainties and inventory [2]. When identifying how smaller ports operate in Scandinavia, it is clear there is no tradition for using P\&C methods. Most planning and execution is done ad-hoc, resulting in nonoptimal utilisation of resources. In addition, a port is a service provider, and is required to have certain resources, so it is important to ensure that these are utilised optimally.

There is a large base of literature relating to the optimisation of larger ports, see review by Stahlbock \& Voß [3], however, Danish ports are small and medium-sized ports, which may make the use of large port literature difficult, as the complexity of the methods in the literature is often on high level.

adfa, p. 1, 2011.

(c) Springer-Verlag Berlin Heidelberg 2011 
Small and medium sized ports have not received much attention either in academia or in politics. One reason is that the focus in maritime transport research has been on globalisation. Especially the Europe/Asia container traffic have received a lot of attention, with ports as Rotterdam, Antwerp, Hong Kong and Shanghai being heavily represented in academia. The literature regarding these ports, have focussed on large-scale operations, with use of very advanced mathematical models and computer systems to control the container terminals [4], [5] and [6]. The problem is not the quality of these methods and models, but rather that smaller ports do not have the resources required to make use of these methods, and that introducing computer systems and mathematical models in ports that are not prepared for this can have negative consequences. Another case for discussion is how much the methods benefit the small ports in terms of monetary and competitive value. With a much lower volume, the total benefit for e.g. a 1\% cost reduction from a mathematical model does not have the same effect as it does in a multimillion-dollar enterprise, in terms of payback.

Therefore, there is a need for developing the small ports both in terms of strategy, but also in terms of planning and coordination, inside the port and in the supply chain. Brooks et al. [7] defines collaboration and coordination as the two most important parameters in smaller ports, collaboration can be defined as the strategic frame for enabling tactical and operational coordination. However since a port is a non-hierarchical system, it might prove difficult to use traditional $\mathrm{P} \& \mathrm{C}$ methods directly.

This paper addresses the issue of using planning and control methods for aligning capacity and demand in smaller ports. This is done by defining and understanding characteristics the port environment and analysing the applicability of $\mathrm{P} \& \mathrm{C}$ functions. The characteristics of a small Danish port will be analysed to find the unique profile and thereby give the opportunity to define how the different production P\&C tools and methods can be applied to a port system. Further, it will provide an understanding of the nature of a port system, which can provide the knowledge of how to optimise and reconfigure it.

\section{Theoretical background}

Keeping the production data such as demand, supply, product, inventory, accounting, costing, lead-time, and routing in an integrated manner, these systems have become the central systems widely implemented in manufacturing environments.

Manufacturing Planning and Control (MPC) is an overall approach, which control everything from material management, scheduling of machine capacity, suppliers, and human resources to find the best solution. Besides the physical material flow, the flow of information also needs to be taken into consideration [2]. MPC Systems are generally described as being divided into three time horizons, these being strategic planning, tactical planning and operational planning [8], [9]. Generally, planning and control (P\&C) aims for matching customer demand with supply of products and materials in terms of timing, volume, and quality [10]. Different $\mathrm{P} \& \mathrm{C}$ paradigms have been proposed in the literature. However, the hierarchical $\mathrm{P} \& \mathrm{C}$ paradigm has become an accepted $\mathrm{P} \& \mathrm{C}$ structure in many medium and large companies [11], by coordinating the material flow and capacity for optimal outputs levels. This paradigm is mainly implemented with the Manufacturing Resource Planning (MRPII) framework, which is the basic logic behind 
the Enterprise Resource Planning (ERP) systems. The majority of the modern manufacturing firms use MRP II/ ERP systems for production P\&C activities [12]. The MRP II framework is a well-known model that consists of interconnected material and capacity $\mathrm{P} \& \mathrm{C}$ functions with hierarchical guidelines, in different time frames and aggregations [2]. As the purpose is to define a P\&C system for smaller ports, this framework will be further analysed.

The MRP II system segments the P\&C tasks in to three time frames; strategic (1-12 months), tactical (1 week - 3 months) and operational (1-5 days), [8]. The structure lies in both the length of the planning horizon as well as the level of data aggregation. The aggregation levels depends on the time horizon, and thereby the uncertainty. P\&C is made for a hierarchical system setup, and since a port is not necessarily a hierarchical system, there might be some challenges in adapting this concept. However, in P\&C the central tasks or functions are generic to any environment. These different planning tasks and functions are required to align a company's setup to the demand for products and handle different parts of the planning processes according to when and where it is required. E.g. aligning capacity of resources with the strategic demand, committing actual demand to different time fences in the production system's capacity and ensuring correct inventory levels at required time fences. Based on primarily Vollmann et. al [2]:

- The long term planning is necessary for planning the overall capacity. This include equipment, buildings, suppliers, and so forth. These decisions set the parameters for responding to current and future customer demand. In the long-term planning phase, Resource Planning, Demand Management, Sales and Operations Planning, and Master Production Scheduling (MPS) functions exists.

- The mid-term planning in MPC combines the detailed material planning and the detailed capacity planning in order to create a plan to satisfy customer demand. This means coordinating the supply and demand with the production capacity, levels of raw material and finished goods. Here the functions involves Detailed Material Planning, Detailed Capacity Planning, and Material and Capacity Plans. To ensure success, it is important to communicate with the customers and the suppliers about expected delivery times and quantities [2].

- In the short-term planning the scheduling of resources (time, people, material, equipment, and facilities) is done on detail, which is required in the production plan. Here the function of the Shop-Floor Systems and the Supplier Systems exists.

All functions have varying importance depending on the environment in which they are applied, and varying detail level. Any environment will therefore have a unique profile depending on its characteristics.

\section{Case description from a port system}

The port system is configured around handling cargo transformation between land and sea, and is made up of several companies handling different tasks. It is necessary to understand how the port system is organised, as this greatly influences how the different tasks are planned and executed, and how information can be propagated in the port system. The amount of autonomous companies present in the operations is one of the larger challenges in attempting to plan tasks in a port. Firstly, the companies mostly 
operate in a craftsman's type fashion where they go from job to job, without planning the activities. This gives some challenges when coordinating the actual move of goods, as there is no clear responsibility as to who have the overall planning responsibility. This is especially true in the situations where there are several actors involved in the port operations, which is most bulk and special cargo transport transformation operations. In the container terminal there is typically one actor, but the interfacing with mainly the landside and the arrival of trucks, presents some of the same coordination challenges, such as the timing of arriving trucks and the placement of containers in the container inventory. To illustrate the different planning functions in the port system, each actor and their involvement in the system are explained:

- Shipping broker: A shipping broker is an agency that provides transport solutions for customers, either by booking transport in the market or by providing some services themselves. In some cases, the shipping agent facilitates the booking of the transport activities and coordination of these activities to meet delivery deadlines etc. In other cases, the shipping agent is only hired to handle the cargo transformation, and the shipping line or other supply chain actor books the necessary transport solutions. Seen from the port system the shipping agent often have a coordinating role.

- Terminal services: This is cranes, dockworkers and other equipment required to services ships and trucks at the dockside. Different companies own these

- Truck transport: These operate within or in connection to the port, the owner of the goods or a shipping broker most often hires these. Currently they arrive when it fits their own plans combined with deadlines for cargo submission and withdrawal in the ports.

- Shipping line: The company that owns and operate the ship. Ships are as trucks often hired by the owner of the cargo or on their behalf hired by brokers. Some ships are however also operating on regular shipping routes. These routes are controlled by the shipping lines and are based on market demand.

- Port authorities: The port authority is the owner of the land and docks. They are also the authority, which control and manage the waters in and around the port, giving permission and overseeing the ships in these waters. Further, they are landlords for most companies operating in the port system.

- Support services: There are many different support services offered to both ships and companies in the port system. Ships can receive supplies, repair crews and other related services. Depending on the service, different companies handle this, and both the port authority and the shipping broker can facilitate contact for the ships.

- Warehousing: Is an essential service in port, as it provides a possibility for creating distribution functions or a temporary storage space when sending and receiving large quantities of goods, which is often the case in ports. Further it also possible to use warehousing as a consolidation function, batching smaller quantities of cargo with other small shipments, so the utilisation of ship and container space becomes higher and the cost lower.

Besides the description of the different resources involved in servicing a ship, Figure 1 gives a simple overview of the resources. The resources are handled by different companies, depending on the types of goods. Common for these resources are that they are 
very expensive, making resource utilisation an important factor. The resources all influence each other as they are used in all operations, which also means that the operations are dependent on each other, underlining the need for coordination.

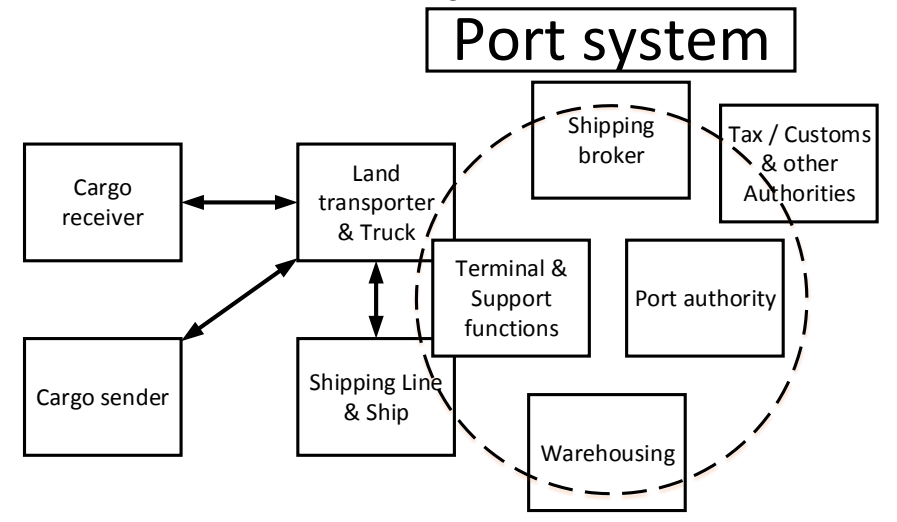

Fig. 1. The boxes are resources and companies, and the circle represents the port system.

One major problem regarding the organisation of resources is the many different owners with different priorities, which means the planning and the coordination is segmented from the resources. Even though, some of the ports P\&C system can be defined on a hieratical level, this is not entire the possible due to the structure of the port system. Furthermore, planning becomes even more challenging as most of the actors in the port system uses calendar based planning, where they put in ship arrivals and make loose plans regarding resources and personnel around these events. The information in the calendar is based on sales orders issued through the shipping agent, and the port authority's monitoring system for approaching ships. However, the information available in the monitoring system is not actively communicated to all parties in an organised way, which means it is not used to keep the existing plans updated. Further, the knowledge about how to handle the specific orders is based on silent knowledge accumulated within the operational staff in the port.

Olesen et al [13] proposes an implementation of a form of centralized platform for information sharing. This will improve the coordination that handles information about the flow of goods. In the current setting there are challenges with communicating this information to the workers early enough to plan other activities before committing resources to service an incoming ship. Also not all resources need to be present as soon as the ship docks. By centralising the information flow, it will be easier to make a feasible plan for the common resources, and thereby easier for companies at the port to plan based on ship arrival and crane and dock availability. However, to ensure the correct use of such an information-sharing tool, it is important to have an overview of the different functions needing information. Therefore, the following will give a structured overview of the planning activities in the port system. 


\section{Defining the planning environment in a port system}

The reason for utilising $\mathrm{P} \& \mathrm{C}$ is to be able to create a model that allows configuration of a planning environment in a port. A review of intermodal operations research have been done by Macharis \& Bontekoning [14], where they also focus on the three time horizons of strategic, tactical and operational which align with the effort in this paper, however, in this paper the planning functions from the MPC are added to be able to relate operations with a planning task. Planning is necessary, as ports are very dynamic environments were a lot of different transport actors come and go every day. This builds in an uncertainty into the system that lacks a mechanism to plan and re-plan activities according to demand and delivery of goods and services in a close to real-time manner. Another issue regarding the lack of $\mathrm{P} \& \mathrm{C}$ in ports is the ability to measure, evaluate and compare operations in the port with other similar ports. By creating a structured environment with variables and functions, the performance control will also be structured and be comparable.

The port system and the cases have been described to show the need for planning and coordination in the small to medium sized port environment. With that in mind the cases are related to the planning functions mentioned in Vollmann [2]. The main challenges found in the case port are:

- Aligning port activity with incoming ships and trucks

- Pushing information about activities in the port to external partners

- Planning of shared resources and individual activities

- Coordination and sequencing

In reference to the case description, it is also evident that the planning functions are relevant in the port environment. However, the use of MRP as the engine is not relevant as there is no BOM and thereby material requirements calculations. Further, the MPC model also implies a hierarchical setup, which is not present in most ports. These factors means that MPC is not directly transferable to this context. However, since it is a system made up of resources, processes, products and demand it is comparable to the MPC when looking purely at the planning functions. The MPC functions are translated in Table 1 to a comparable function in a port setting. It is important to stress that it is only the concept of aligning capacity and demand in all planning faces, and this approach does not expect to make use of all methods and tools attributed to each planning function in a $\mathrm{P} \& \mathrm{C}$ environment.

The frame of the MPC model is very descriptive of what is relevant when planning in any type of environment, as it at simplest is a time fencing of activities segmented into resources, capacity and materials. In the port system, resources and capacity also apply and materials are the goods passing through the port.

The MPC framework is hierarchical, which the port system is not. Therefore, this cannot be applied directly on the port system. However, all planning activities are still relevant to all industries. Therefore, only the hierarchical perspective of the framework cannot be applied. Table 1 shows the function of the port system applied in a P\&C contests, with especially focus on the MPC framework.

Relating the port system to the planning functions and the time frames, it becomes evident that one of the major challenges is to assign responsibility for the different 
planning functions. However, since the port system is fragmented, most of these functions in the strategic and tactical layer would have to be handled by the port authority and the shipping broker, as these have contact with all partners.

Table 1. An interpretation of the MPC system in a port context.

\begin{tabular}{l|l|l}
\hline Port Function & MPC Function & Purpose \\
\hline $\begin{array}{l}\text { Port System Plan- } \\
\text { ning }\end{array}$ & $\begin{array}{l}\text { Sales and opera- } \\
\text { tions planning }\end{array}$ & $\begin{array}{l}\text { The port strategy based on input from demand } \\
\text { and resource planning (Strategic) }\end{array}$ \\
\hline $\begin{array}{l}\text { Resource Plan- } \\
\text { ning }\end{array}$ & $\begin{array}{l}\text { Resource plan- } \\
\text { ning }\end{array}$ & $\begin{array}{l}\text { The alignment of resources to port strategy and } \\
\text { forecasted demand (Strategic) }\end{array}$ \\
\hline $\begin{array}{l}\text { Hinterland man- } \\
\text { agement }\end{array}$ & $\begin{array}{l}\text { Demand manage- } \\
\text { ment }\end{array}$ & $\begin{array}{l}\text { Creating and finding demand in the port's hinter- } \\
\text { land (Strategic) }\end{array}$ \\
\hline $\begin{array}{l}\text { Port system ca- } \\
\text { pacity check }\end{array}$ & $\begin{array}{l}\text { Master production } \\
\text { scheduling }\end{array}$ & $\begin{array}{l}\text { The aggregation of the strategic demand sorted } \\
\text { into time fences with capacity check on the re- } \\
\text { sources. (Tactical) }\end{array}$ \\
\hline Port Data System & $\begin{array}{l}\text { Detailed material } \\
\text { planning }\end{array}$ & $\begin{array}{l}\text { The commitment of resources to certain ship arri- } \\
\text { vals in a common data platform. (Tatical) }\end{array}$ \\
\hline $\begin{array}{l}\text { Port capacity } \\
\text { planning }\end{array}$ & $\begin{array}{l}\text { Detailed capacity } \\
\text { planning }\end{array}$ & $\begin{array}{l}\text { Booking of capacity in relations to production or- } \\
\text { ders within time fences. (Tactical) }\end{array}$ \\
\hline Arrival manifest & $\begin{array}{l}\text { Material and ca- } \\
\text { pacity plans }\end{array}$ & $\begin{array}{l}\text { List of ship arrivals, with details of cargo and ac- } \\
\text { tors, sorted into time fences. (Tactical) }\end{array}$ \\
\hline $\begin{array}{l}\text { Coordination/ se- } \\
\text { quencing }\end{array}$ & $\begin{array}{l}\text { Shop floor sys- } \\
\text { tems }\end{array}$ & $\begin{array}{l}\text { The order and timing of actions and the execu- } \\
\text { tion of these (Operational) }\end{array}$ \\
\hline Port Data system & Vendor systems & $\begin{array}{l}\text { Information sharing system between all actors re- } \\
\text { lated to specific jobs. (Operational) }\end{array}$ \\
\hline
\end{tabular}

\section{$5 \quad$ Discussion and Conclusion}

The paper discuss $\mathrm{P} \& \mathrm{C}$ as a method for coordinating activities in a port. The elements of the well-described MPC are used to illustrate the planning functions and the aggregations levels. Because of the expectation of a hierarchical system structure in the MPC model, it is not entirely applicable to the non-hierarchical port system. However, the general purpose of the planning functions is to align capacity and demand in different aggregations, and this is what the port system need. Therefore, the port system should make use of the overall approach of the MPC planning functions, placed in the port context as in Table 1. The motivation behind this approach is to utilise a well-known model to create a general approach for ports to align their activities. Some of the elements within the MPC model are not relevant in relation to a port service system, such as the MRP logic, but the method for aligning capacity and demand on the three different time scales, is highly relevant.

When the timing of a ship arrival changes the information has difficulty permeating through the port system. The reason for this is two-fold, firstly is the lack of information sharing amongst the partners. Secondly is the lack of methods to understand, plan and re-plan the activities based on the available information. This is why the ability to think 
in strategic, tactical and operational time frames are essential, as well as the ability to match capacity with demand and operational execution.

To utilise the P\&C features, a method is created that will allow a structured approach to identify how to handle certain events within a $\mathrm{P} \& \mathrm{C}$ system. This is done by defining the tasks in a port, e.g. loading and unloading containers, stone or grain. The difference between these tasks is not large, but the demand and supply structures are different, and the need for equipment and resources are also different. Further, each type of goods going through the port have a unique requirement in terms of services and tools required to perform these services.

This paper presents a new way of looking at planning and coordination in a port and this method needs to be tested in a port system. Further, a framework based on these findings needs to be created, in order to present a planning and coordination model that applies fully to a port system, considering the non-hierarchical structure.

\section{References}

1. Beresford AKC, Gardner BM, Pettit SJ, et al. (2004) The UNCTAD and WORKPORT models of port development: evolution or revolution? Marit Policy Manag 31:93-107. doi: 10.1080/0308883042000205061

2. Vollmann TE, Berry WL, Whybark DC, Jacobs FR (2004) MANUFACTURING PLANNING AND CONTROL SYSTEMS FOR SUPPLY CHAIN MANAGEMENT: The Definitive Guide for Professionals, 5th ed. McGraw-Hill Professional

3. Stahlbock R, Voß S (2007) Operations research at container terminals: a literature update. Spectr 30:1-52. doi: 10.1007/s00291-007-0100-9

4. Kia M, Shayan E, Ghotb F (2002) Investigation of port capacity under a new approach by computer simulation. Comput Ind Eng 42:533-540. doi: 10.1016/S03608352(02)00051-7

5. Tahar RM, Hussain K (2000) Simulation and analysis for the Kelang Container Terminal operations. Logist Inf Manag 13:14-20. doi: 10.1108/09576050010306350

6. Ng WC, Mak KL (2005) Yard crane scheduling in port container terminals. Appl Math Model 29:263-276. doi: 10.1016/j.apm.2004.09.009

7. Brooks MR, McCalla RJ, Pallis AA, van der Lugt LM (2010) Coordination and Cooperation in Strategic Port Management: The Case of Atlantic Canada's Ports. work 902:4941825.

8. Silver EA, Pyke DF, Peterson R, others (1998) Inventory management and production planning and scheduling. Wiley New York

9. Koh SCL, Gunasekaran A (2006) A knowledge management approach for managing uncertainty in manufacturing. Ind Manag Data Syst 106:439-459. doi: $10.1108 / 02635570610661561$

10. Slack N, Chambers S, Johnston R (2010) Operations Management. Pearson Education

11. McKay KN, Wiers VCS (2003) Planning, scheduling and dispatching tasks in production control. Cogn Technol Work 5:82-93. doi: 10.1007/s10111-002-0117-4

12. M. Stevenson, L. C. Hendry, B. G. Kingsman (2005) A review of production planning and control: the applicability of key concepts to the make-to-order industry. Int J Prod Res 43:869-898. doi: 10.1080/0020754042000298520

13. Olesen PB (2014) Framework for Information sharing in a Small-to-medium Port System Supply Chain. Adv. Prod. Manag. Syst. Innov. Knowl.-Based Prod. Manag. Glob.-Local World 2014:

14. Macharis C, Bontekoning YM (2004) Opportunities for OR in intermodal freight transport research: A review. Eur J Oper Res 153:400-416. doi: 16/S0377-2217(03)00161-9 